\title{
Differential Mechanisms of Ang (1-7)-Mediated Vasodepressor Effect in Adult and Aged Candesartan-Treated Rats
}

\author{
S. Bosnyak, ${ }^{1}$ R. E. Widdop, ${ }^{1}$ K. M. Denton, ${ }^{2}$ and E. S. Jones ${ }^{1}$ \\ ${ }^{1}$ Departments of Pharmacology, Monash University, Clayton, VIC 3800, Australia \\ ${ }^{2}$ Departments of Physiology, Monash University, Clayton, VIC 3800, Australia \\ Correspondence should be addressed to R. E. Widdop, robert.widdop@monash.edu
}

Received 29 July 2011; Accepted 7 September 2011

Academic Editor: Robson Santos

Copyright ( $) 2012$ S. Bosnyak et al. This is an open access article distributed under the Creative Commons Attribution License, which permits unrestricted use, distribution, and reproduction in any medium, provided the original work is properly cited.

\begin{abstract}
Angiotensin (1-7) (Ang (1-7)) causes vasodilator effects in Wistar-Kyoto (WKY) rats and spontaneously hypertensive rats (SHRs) via angiotensin type 2 receptors $\left(\mathrm{AT}_{2} \mathrm{R}\right)$. However, the role of vascular $\mathrm{AT}_{2} \mathrm{R}$ in aging is not known. Therefore, we examined the effect of aging on Ang (1-7)-mediated vasodepressor effects and vascular angiotensin receptor localization in aging. Blood pressure was measured in conscious adult ( $\sim 17$ weeks) and aged ( $\sim 19$ months) normotensive rats that received drug combinations in a randomised fashion over a 4-day protocol: (i) Ang (1-7) alone, (ii) $\mathrm{AT}_{1} \mathrm{R}$ antagonist, candesartan, alone, (iii) Ang (1-7) and candesartan, or (iv) Ang-(1-7), candesartan, and the $\mathrm{AT}_{2} \mathrm{R}$ antagonist, PD123319. In a separate group of animals, the specific MasR antagonist, A779, was administered in place of PD123319. Receptor localisation was also assessed in aortic sections from adult and aged WKY rats by immunofluorescence. Ang (1-7) reduced blood pressure $(\sim 15 \mathrm{mmHg})$ in adult normotensive rats although this effect was dependant on the background dose of candesartan. This depressor effect was reversed by $\mathrm{AT}_{2} \mathrm{R}$ blockade. In aged rats, the depressor effect of Ang (1-7) was evident but was now inhibited by either $\mathrm{AT}_{2} \mathrm{R}$ blockade or MasR blockade. At the same time, $\mathrm{AT}_{2} \mathrm{R}, \mathrm{Mas} \mathrm{R}$, and ACE2 immunoreactivity was markedly elevated in aortic sections from aged animals. These results indicate that the Ang (1-7)-mediated depressor effect was preserved in aged animals. Whereas Ang (1-7) effects were mediated exclusively via stimulation of $\mathrm{AT}_{2} \mathrm{R}$ in adult WKY, with aging the vasodepressor effect of Ang (1-7) involved both $\mathrm{AT}_{2} \mathrm{R}$ and Mas $\mathrm{R}$.
\end{abstract}

\section{Introduction}

It is well known that Angiotensin II (Ang II) mediates its physiological functions via two main receptor subtypes, the type $1\left(\mathrm{AT}_{1} \mathrm{R}\right)$ and type $2\left(\mathrm{AT}_{2} \mathrm{R}\right)$ angiotensin receptors where it has similar affinity for both the $\mathrm{AT}_{1} \mathrm{R}$ and $\mathrm{AT}_{2} \mathrm{R}$. However, there is now increasing evidence suggesting that angiotensin peptides other than Ang II can evoke cardiovascular effects that oppose the effects mediated by the $\mathrm{AT}_{1} \mathrm{R}$ via a number of non- $\mathrm{AT}_{1} \mathrm{R}$ mechanisms. In fact, heptapeptide Angiotensin (1-7), (Ang (1-7)), a biologically active metabolite of angiotensin I (Ang I) and Ang II $[1,2]$ has been shown to possess biological activity in its own right [3]. Interest in Ang (1-7) has surged since the discovery of angiotensin converting enzyme type 2 (ACE2) and recognition that Ang (1-7) can be produced directly from Ang II via ACE2 [1, 2]. Although, Ang (1-7) differs to Ang II by only one amino acid, Ang (1-7)-mediated effects are markedly different to those of Ang II, and it has been suggested that Ang (1-7) may in fact play a counterregulatory role to Ang II [4], mediating a range of effects such as vasodilatation, inhibition of vascular smooth muscle proliferation, and fluid and electrolyte homeostasis [5]. The cardiovascular effects of Ang (1-7) are often reported to be inhibited by the D-Ala ${ }^{7}$ Ang (1-7) analogue, known as A779 [6]. Recently, Ang (1-7) was identified as an endogenous ligand for the Ang (1-7)/MasR (MasR), since Ang (1-7)-mediated vasorelaxation was impaired in Mas $\mathrm{R}^{-/-}$mice [7]. However, under some circumstances, Ang (1-7) can mediate its effects via $\mathrm{AT}_{2} \mathrm{R}$ [8-10]. In fact, we have shown that Ang (1-7)-mediated vasodepressor effect was via an $\mathrm{AT}_{2} \mathrm{R}$ sensitive pathway [11]. In that study, Ang (1-7) acutely lowered blood pressure in spontaneously hypertensive rats (SHRs) and Wistar-Kyoto (WKY) adult rats during concomitant $\mathrm{AT}_{1} \mathrm{R}$ blockade, [11] in a similar manner to that seen with $\mathrm{AT}_{2} \mathrm{R}$ agonist, CGP42114 [12, 13], and more recently with selective nonpeptide $\mathrm{AT}_{2} \mathrm{R}$ agonist, 
TABLE 1: Resting MAP recorded on separate days before drug treatments, as indicated.

\begin{tabular}{|c|c|}
\hline Treatment & MAP (mmHg) \\
\hline \multicolumn{2}{|l|}{ Group $1(n=4)$} \\
\hline Saline & $132 \pm 14$ \\
\hline Ang-(1-7) (15 pmol/kg/min) & $124 \pm 4$ \\
\hline Candesartan $(0.01 \mathrm{mg} / \mathrm{kg})$ & $131 \pm 6$ \\
\hline Ang-(1-7) and candesartan & $134 \pm 4$ \\
\hline \multicolumn{2}{|l|}{ Group $2(n=7)$} \\
\hline Saline & $131 \pm 13$ \\
\hline Ang-(1-7) (15 pmol/kg/min $)$ & $136 \pm 13$ \\
\hline Candesartan $(0.01 \mathrm{mg} / \mathrm{kg})$ & $126 \pm 15$ \\
\hline Ang-(1-7) and candesartan & $136 \pm 16$ \\
\hline \multicolumn{2}{|l|}{ Group $3(n=6)$} \\
\hline Ang-(1-7) (15 pmol/kg/min) & $138 \pm 8$ \\
\hline Candesartan $(0.1 \mathrm{mg} / \mathrm{kg})$ & $135 \pm 8$ \\
\hline Ang-(1-7) and candesartan & $139 \pm 11$ \\
\hline Ang-(1-7), candesartan, and PD123319 (50 $\mu \mathrm{g} / \mathrm{kg} / \mathrm{min})$ & $139 \pm 5$ \\
\hline \multicolumn{2}{|l|}{ Group $4(n=7)$} \\
\hline Ang-(1-7) (15 pmol/kg/min) & $143 \pm 10$ \\
\hline Candesartan $(0.1 \mathrm{mg} / \mathrm{kg})$ & $142 \pm 10$ \\
\hline Ang-(1-7) and candesartan & $142 \pm 9$ \\
\hline Ang-(1-7), candesartan, and PD123319 $(50 \mu \mathrm{g} / \mathrm{kg} / \mathrm{min})$ & $137 \pm 9$ \\
\hline \multicolumn{2}{|l|}{ Group $5(n=8)$} \\
\hline Ang-(1-7) (15 pmol/kg/min) & $128 \pm 11$ \\
\hline Candesartan $(0.1 \mathrm{mg} / \mathrm{kg})$ & $122 \pm 10$ \\
\hline Ang-(1-7) and candesartan & $133 \pm 5$ \\
\hline Ang-(1-7), candesartan, and A779 (15 pmol/kg/min) & $132 \pm 2$ \\
\hline \multicolumn{2}{|l|}{ Group $6(n=8)$} \\
\hline Ang-(1-7) (15 pmol/kg/min) & $129 \pm 5$ \\
\hline Candesartan $(0.01 \mathrm{mg} / \mathrm{kg})$ & $126 \pm 10$ \\
\hline Ang-(1-7) and candesartan & $132 \pm 6$ \\
\hline Ang-(1-7), candesartan, and A779 (15 pmol/kg/min) & $125 \pm 8$ \\
\hline
\end{tabular}

Values are \pm SEM.

Compound 21 [14]. Furthermore, the $\mathrm{AT}_{2} \mathrm{R}$ antagonist, PD123319, but not the MasR antagonist, A779, blocked this vasodepressor effect of Ang (1-7) [11].

While it is well recognized that the renin-angiotensin system (RAS) has a critical role in the cardiovascular system; its role in the aging process is still under investigation. During aging, circulating levels of Ang II are downregulated while local production of Ang II is increased in the aorta and other vessels [15] suggesting an essential role of local RAS in the vasculature during aging. However, there is little functional evidence about angiotensin receptors and their role during aging. In this context, we have shown that $\mathrm{AT}_{2} \mathrm{R}$ expression was increased in both endothelial and vascular smooth muscle of aortae obtained from aged WKY rats [16].

Given that there was an increased vascular $\mathrm{AT}_{2} \mathrm{R}$ expression in aging [16], the current study was designed to test our hypothesis that $\mathrm{AT}_{2} \mathrm{R}$-mediated depressor function was preserved with aging. In the present study, we have used Ang (1-7) as an endogenous ligand for the $\mathrm{AT}_{2} \mathrm{R}$, as we have previously reported in adult rats [11]. In preliminary experiments, we have determined that vascular expression of both $\mathrm{AT}_{2} \mathrm{R}$ and MasR/ACE2 axis was upregulated with aging. Therefore, this strategy of using Ang (1-7) will also determine whether or not there was a role for MasR to evoke vasodepressor effects with aging.

\section{Methods}

2.1. Animals. All animal care and experimental procedures were approved by the Monash University Animal Ethics Committee and performed according to the guidelines of the National Health and Medical Research Council of Australia for animal experimentation.

16- to 18-week-old WKY male rats ( 300 to $350 \mathrm{~g}$ ) and 20-month-old WKY male rats $(450-500 \mathrm{~g})$ were obtained from the Animal Resource Centre (Perth, Wash, USA) and were used to represent adult and aged normotensive rats, respectively. Animals were maintained on a 12-hour day/ night cycle with standard laboratory rat chow and water available ad libitum. 


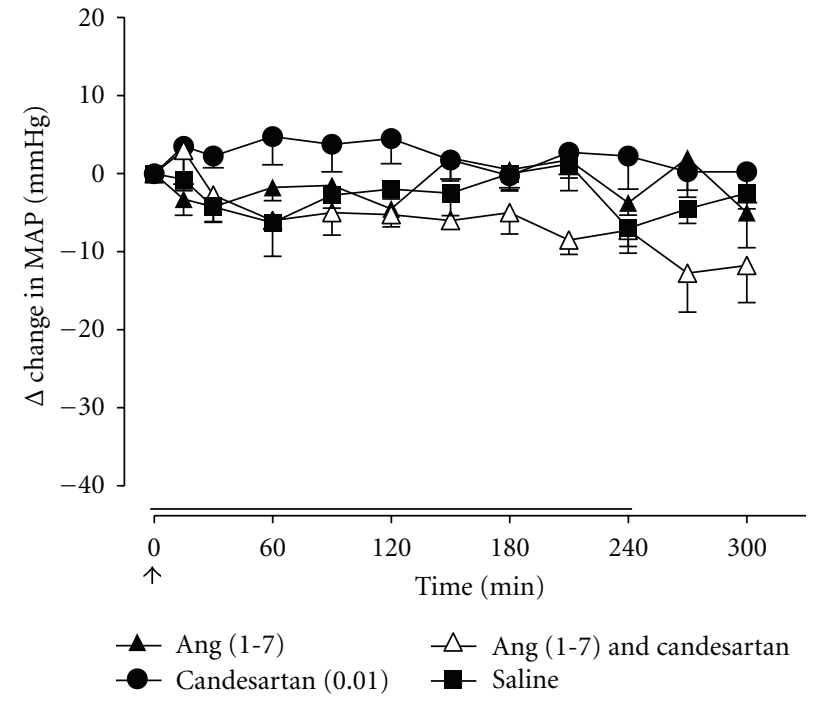

(a)

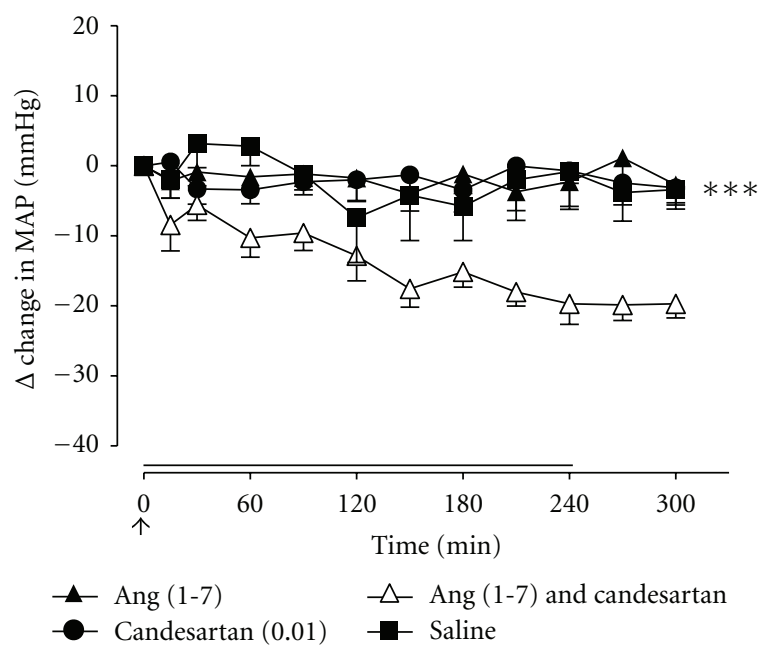

(b)

Figure 1: Effect of the $\mathrm{AT}_{1} \mathrm{R}$ Ang (1-7) (15 pmol/kg/min; 4-hour infusion depicted by full line), $\mathrm{AT}_{1} \mathrm{R}$ antagonist, candesartan (0.01 mg/kg bolus IV; depicted by an arrow), saline $(0.1 \mathrm{~mL} / \mathrm{kg} 0.9 \% \mathrm{NaCl}$ IV for 4 hours), and Ang (1-7) + candesartan on MAP in (a) adult WKY rats $(n=4)$ and $(\mathrm{b})$ aged WKY rats $(n=7)$. Values represent mean \pm SEM. ${ }^{* * *} P<0.001$, for treatment effect of Ang (1-7) + candesartan versus all other treatments (2-way RM ANOVA).

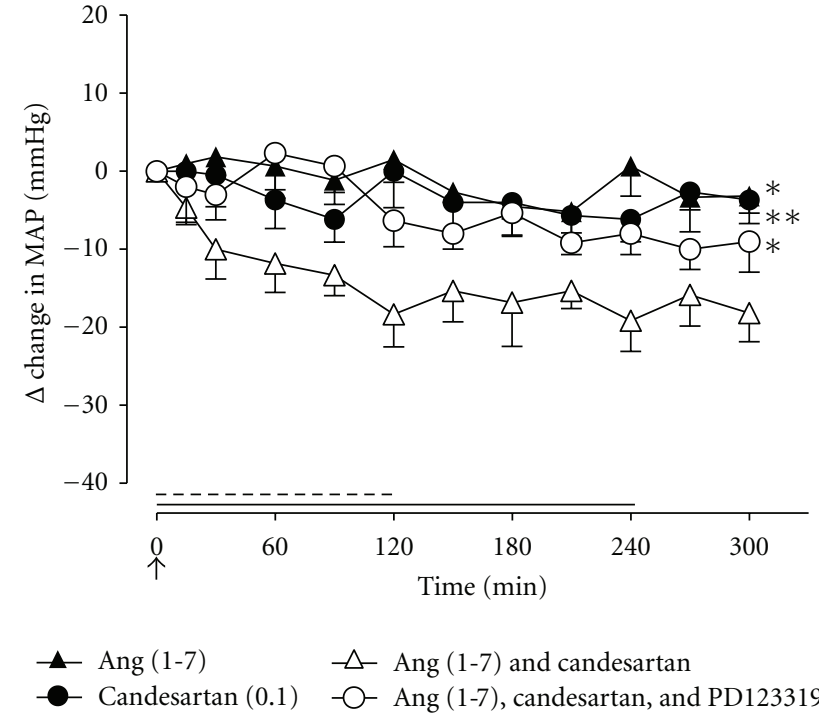

(a)

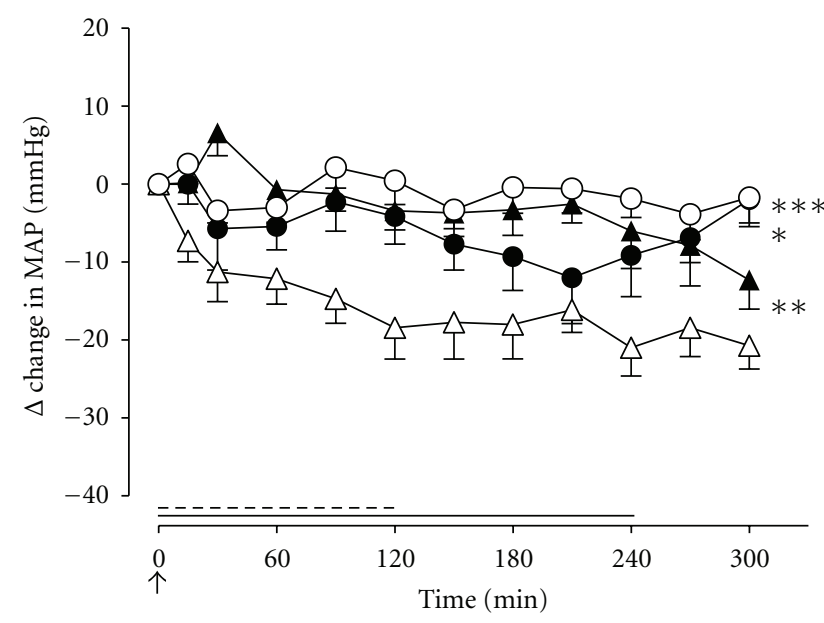

- Ang (1-7)
- Candesartan $(0.1)$

$\triangle$ Ang (1-7) and candesartan

- Ang (1-7), candesartan, and PD123319

(b)

Figure 2: Effect of Ang (1-7) (15 pmol/kg/min; 4-hour infusion depicted by full line), $\mathrm{AT}_{1} \mathrm{R}$ antagonist, candesartan (0.1 mg/kg bolus IV; depicted by an arrow), Ang (1-7) + candesartan, and Ang (1-7) + candesartan $+\mathrm{AT}_{2} \mathrm{R}$ antagonist, PD123319 (50 $\mu \mathrm{g} / \mathrm{kg} / \mathrm{min}$ for $2 \mathrm{hours}$; depicted by dashed line), on MAP in (a) adult WKY rats $(n=6)$ and (b) aged WKY rats $(n=7)$. Values represent mean \pm SEM. ${ }^{*} P<0.05$; ${ }^{* *} P<0.01$; ${ }^{* *} P<0.001$, for treatment effect of Ang (1-7) + candesartan versus all other treatments as indicated (2-way RM ANOVA).

2.2. In Vivo Procedures. Rats were anesthetised (ketamine and xylazine; $75 \mathrm{mg} / \mathrm{kg}$ and $10 \mathrm{mg} / \mathrm{kg}$, i.p, resp.; supplemented as required). Two catheters were inserted into the right jugular for intravenous drug administration. A catheter was implemented into the right carotid artery for direct blood pressure measurement as described previously [1114]. Rats were housed in individual cages and allowed free access to food and water while maintained on 12-hour day/ night cycle. The arterial catheter was infused overnight with heparinised saline using an infusion pump.

24 hours after the surgery, the arterial catheter was attached to a pressure transducer (Gould Inc), connected to a MacLab-8 data acquisition system (ADInstruments, Sydney), interfaced to a Macintosh computer. Mean arterial pressure 


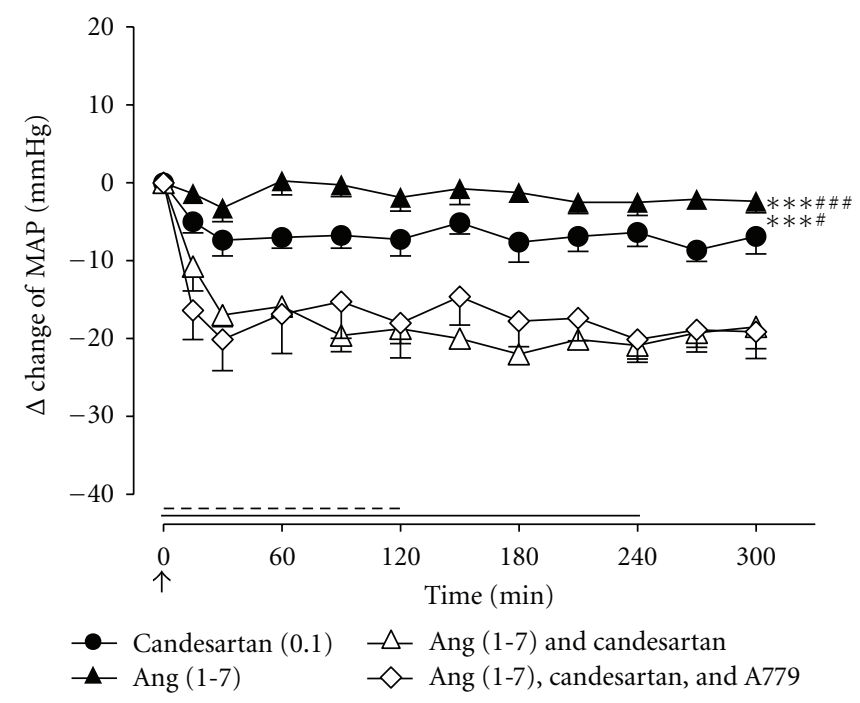

(a)

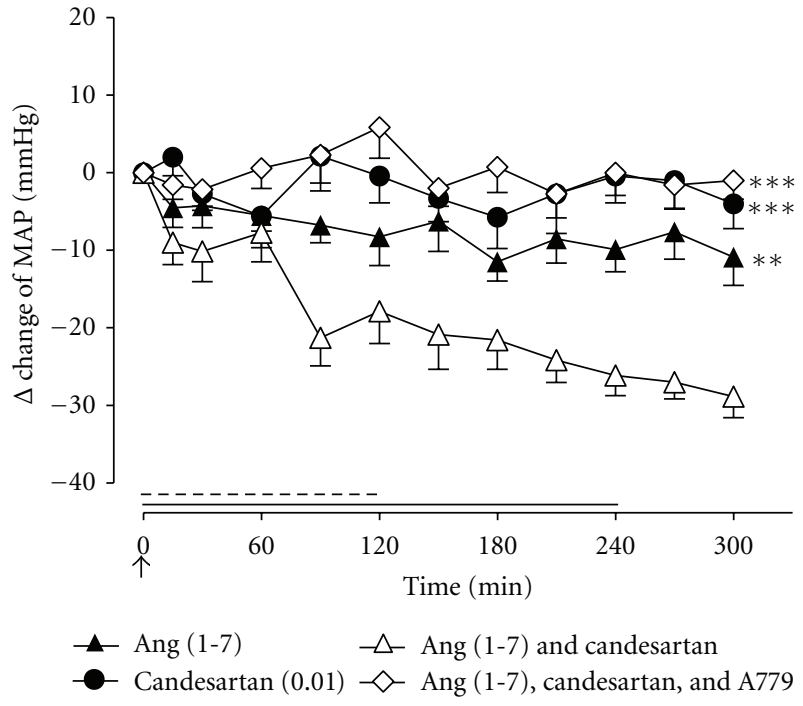

(b)

FIGURE 3: Effect of Ang (1-7) (15 pmol/kg/min; 4-hour infusion depicted by full line), $\mathrm{AT}_{1} \mathrm{R}$ antagonist, and candesartan in (a) adult WKY rats $(0.1 \mathrm{mg} / \mathrm{kg}$ bolus IV; depicted by an arrow) and (b) aged WKY rats $(0.01 \mathrm{mg} / \mathrm{kg}$ bolus IV; depicted by an arrow), together with Ang (1-7) + candesartan and Ang (1-7) + candesartan + MasR antagonist A779 (15 pmol/ $\mathrm{kg} / \mathrm{min}$ for 2 hours; depicted by dashed line), on MAP ( $n=8$ for both groups). Values represent mean \pm SEM. (a) ${ }^{* * *} P<0.001$, for treatment effect of Ang (1-7) + candesartan versus Ang (1-7) or candesartan alone (2-way RM ANOVA), ${ }^{\dagger}<0.05$; ${ }^{\dagger \dagger \dagger}<0.001$, for treatment effect of Ang (1-7) + candesartan + A779 versus candesartan or Ang (1-7) alone (2-way RM ANOVA). (b) ${ }^{* *} P<0.01$; ** $<0.001$ for treatment effect of Ang (1-7) + candesartan versus Ang (1-7), candesartan, or Ang (1-7) + candesartan + A779 (2-way RM ANOVA).

(MAP) and heart rate (HR) were computed from the phasic blood pressure signal.

2.3. Experimental Protocol. Rats received drug combinations in a randomised fashion over a 4-day protocol, as we have performed previously $[11,12,14]$. Doses for candesartan and PD123319 were chosen on the basis of previous studies $[11,12,14]$. Six groups of rats underwent experimental protocols during which basal MAP and HR were recorded. Adult and aged WKY rats (Groups 1 and 2, resp.) were randomized to receive the following treatments on different days: (1) candesartan $(0.01 \mathrm{mg} / \mathrm{kg})$, (2) Ang (1-7) infusion (15 pmol/kg per minute for 4 hours), (3) Ang (1-7) infusion together with candesartan, and (4) a 4-hour infusion $(0.1 \mathrm{~mL} / \mathrm{kg}$ per hour IV) of saline $(0.9 \% \mathrm{NaCl})$ to confirm a lack of effect on MAP. Animals in Group 3 (adult WKY rats) and Group 4 (aged WKY rats) were randomized to receive the following treatments: (1) candesartan at a 10-fold higher dose $(0.1 \mathrm{mg} / \mathrm{kg})$, (2) Ang (1-7) infusion (15 pmol/kg per minute for 4 hours), (3) Ang (1-7) infusion together with candesartan, and (4) Ang (1-7) infusion in the presence of candesartan and PD123319 infusion $(50 \mu \mathrm{g} / \mathrm{kg}$ per minute for 2 hours). In analogous experiments in additional adult and aged WKY rats (Groups 5 and 6), the putative Ang (1-7) antagonist, A779 (15 pmol/kg per minute), was used instead of PD123319. Doses of Ang (1-7) and A779 are based on our previous study [11].

2.4. Localization of $A C E 2, A T_{1}, A T_{2}$, and Mas Receptors. Localization of $\mathrm{ACE} 2, \mathrm{AT}_{1}, \mathrm{AT}_{2}$, and Mas receptors using immunofluorescence was performed using thoracic aortic sections taken from naïve aged and adult rats to determine changes in expression levels between the two age groups. Male adult and aged WKY rats were killed by isoflurane inhalation followed by decapitation, and the thoracic aorta was removed in order to dissect $3-5 \mathrm{~mm}$ long sections. Immunofluorescence was performed using $10 \mu \mathrm{m}$ thick section of thoracic aorta cut on Cryostat. Aortic sections were incubated overnight at $4{ }^{\circ} \mathrm{C}$ with $1 / 500$ dilution of polyclonal rabbit antibodies raised against $\mathrm{AT}_{1} \mathrm{R}, \mathrm{AT}_{2} \mathrm{R}$, MasR, and ACE2. Following overnight incubation, sections were incubated for 2.5 hour with a goat anti-rabbit secondary antibody conjugated with Alexa 568 flurophore. Rabbit IgG antibody was used as negative control. Sections were mounted with antifade medium (VectorShield) and cover slipped. Sections were imaged using Olympus Fluoview 500 confocal microscope equipped with a krypton/argon laser. Fluorescence intensity was quantified using analysis professional software (Soft Imaging System, Singapore) with identical measurement settings.

2.5. Statistical Analysis. All data are presented as mean responses \pm standard error of the mean (SEM). Differences in MAP between treatments were analysed using a 2-way ANOVA repeated measure analysis of variance. Differences in fluorescence intensity were analysed using 1-way ANOVA with Bonferroni corrections where appropriate. Statistical analysis was performed using GraphPad Prism (Version 5.0c). $P$ values $<0.05$ were deemed statistically significant. 


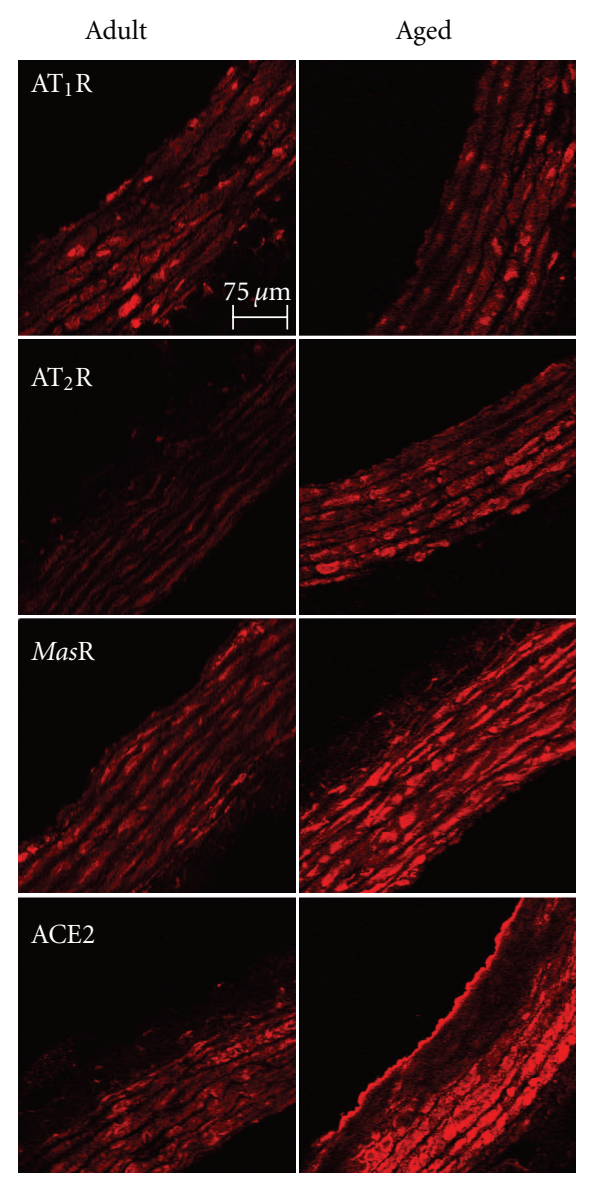

(a)

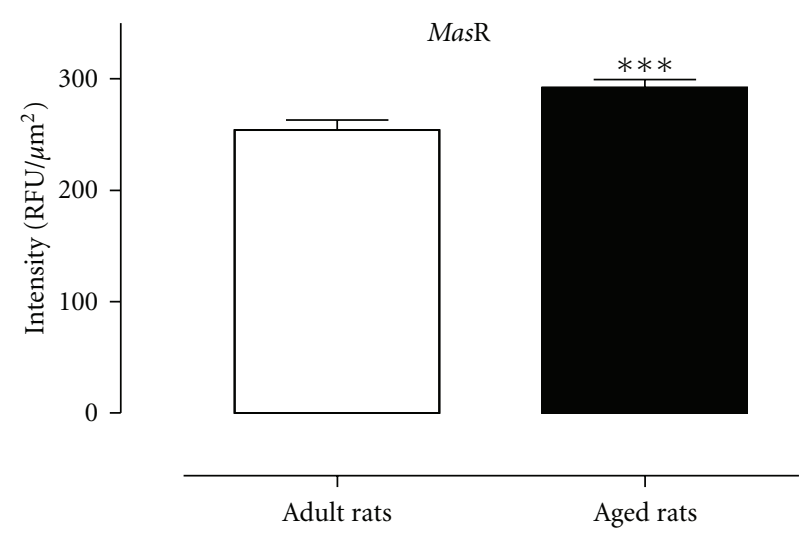

(d)

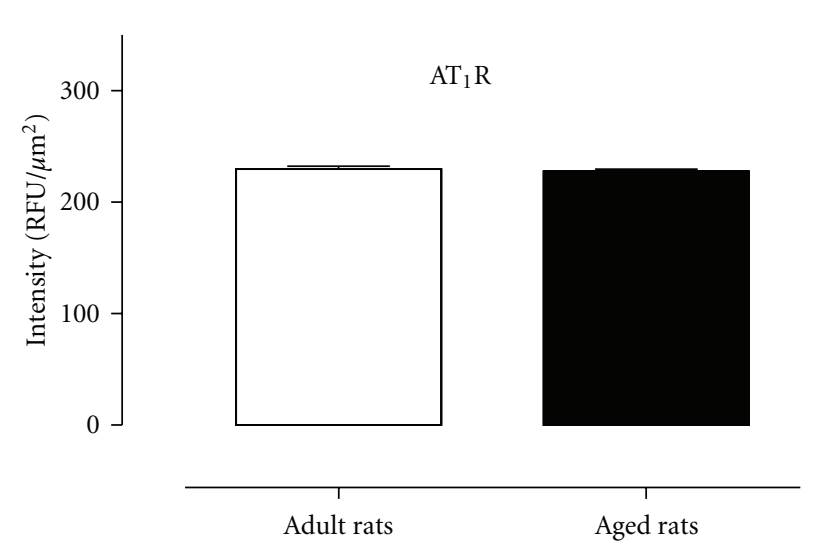

(b)

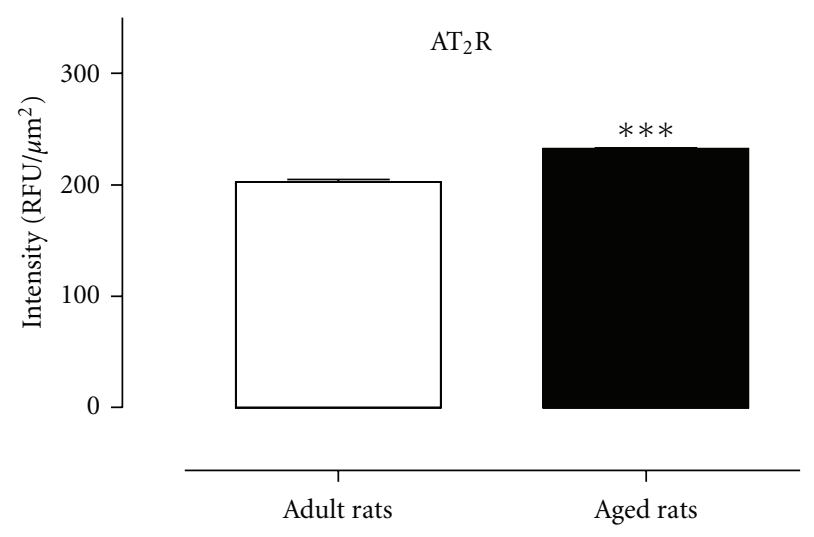

(c)

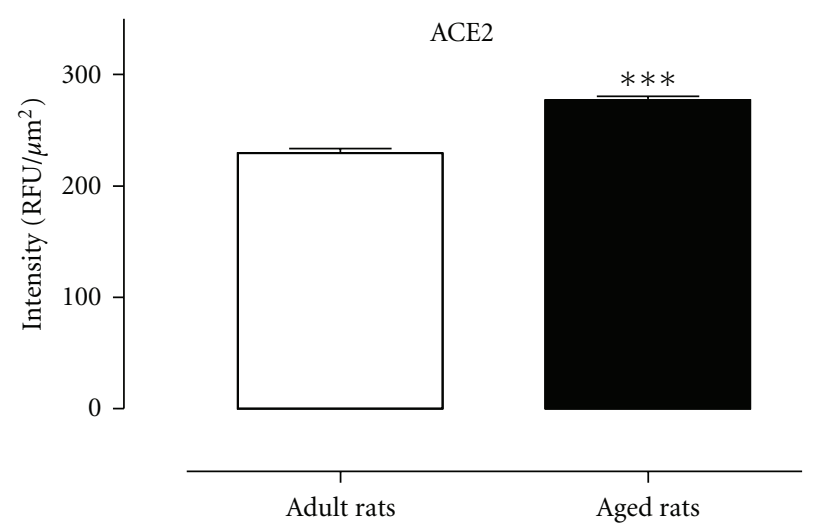

(e)

FIGURE 4: (a) Representative immunolocalisation images of $\mathrm{AT}_{1} \mathrm{R}, \mathrm{AT}_{2} \mathrm{R}, \mathrm{Mas}$, and $\mathrm{ACE} 2$ in adult WKY rats and aged WKY rats. Mean data for aortic expression of the (b) $\mathrm{AT}_{1} \mathrm{R},(\mathrm{c}) \mathrm{AT}_{2} \mathrm{R},(\mathrm{d})$ MasR, and (e) ACE2 expressed as relative fluorescent units in adult $(n=5)$ and aged $(n=4) \mathrm{WKY}$ rats. ${ }^{* * *} P<0.001$ versus adult WKY rats.

2.6. Materials. PD123319 and candesartan were kind gifts from Pfizer and AstraZeneca, respectively. All other chemicals were purchased from commercial sources: ketamine (Troy Laboratories, Australia), xylazine (Troy Laboratories), isoflurane (Baxter, USA), Ang (1-7) (Ausep, Australia), A779 (Auspep, Australia), rabbit polyclonal antibodies raised against $\mathrm{AT}_{1} \mathrm{R}, \mathrm{AT}_{2} \mathrm{R}$, and $\mathrm{ACE} 2$ (Santa Cruz Biotechnology Inc., Catalogue no. SC1173, SC9040, and SC2099), rabbit polyclonal antibody raised against MasR (Novus Biologicals, USA, Catalogue no. NLS1531), secondary goat anti-rabbit Alexa 568 antibody (Invitrogen, USA, Catalogue no. A21069). 


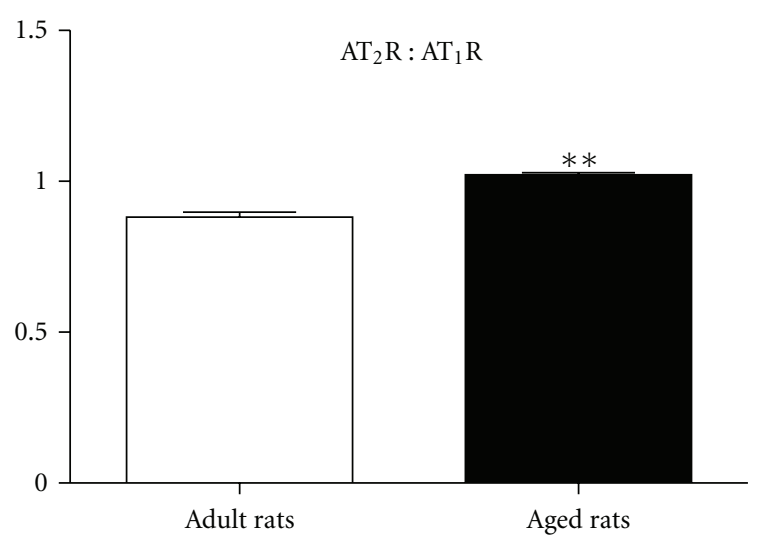

(a)

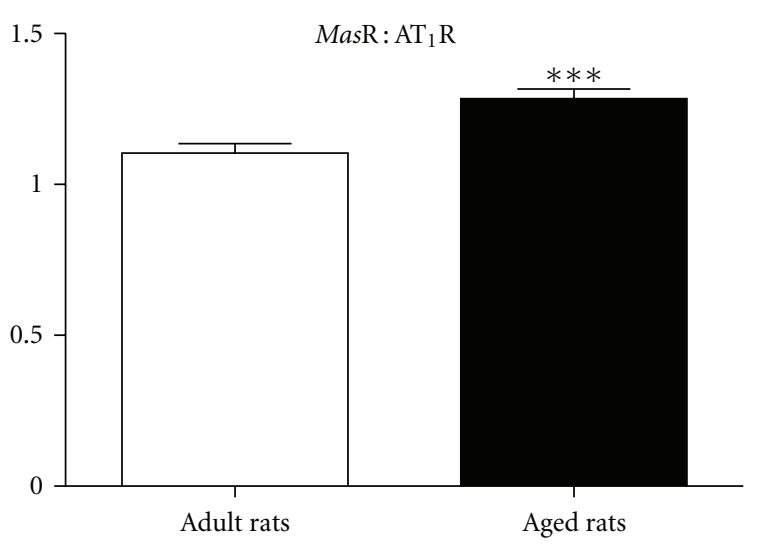

(b)

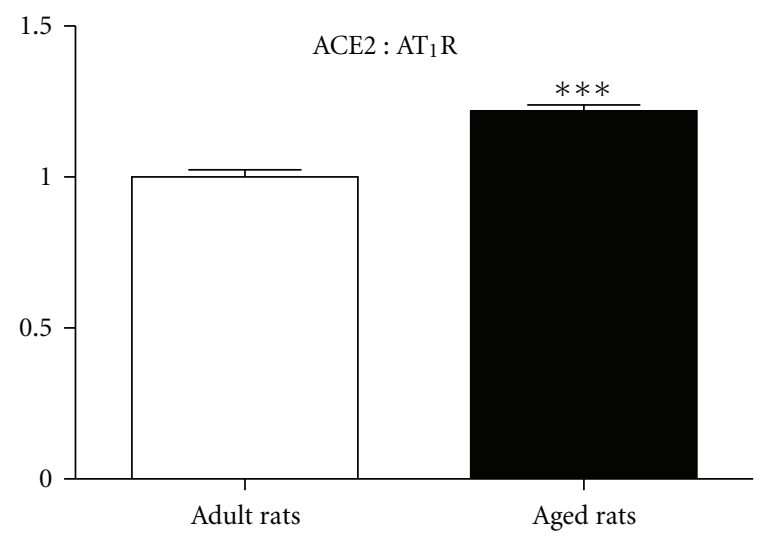

(c)

Figure 5: Ratios of (a) $\mathrm{AT}_{2} \mathrm{R}: \mathrm{AT}_{1} \mathrm{R}$, (b) Mas R: $\mathrm{AT}_{1} \mathrm{R}$, and (c) $\mathrm{ACE} 2: \mathrm{AT}_{1} \mathrm{R}$ in adult and aged WKY rats. ${ }^{* *} P<0.01$; ${ }^{* * *} P<0.001$ versus adult WKY rats.

\section{Results}

3.1. In Vivo Effect of Ang (1-7) in Conscious Normotensive Rats. Basal MAPs of WKY rats over the 4 experimental days for each group are listed in Table 1. There was no significant difference between resting MAPs over the experimental period for any of the treatment groups, suggesting that none of the acute treatments had long-lasting effects and, therefore, did not influence baseline MAP on subsequent days.

In groups 1 and 2, infusion of saline had no significant effect on MAP (Figure 1). Therefore, this treatment was not performed in subsequent groups in order to include additional treatment arms. In all groups, infusion of Ang (1-7) $(15 \mathrm{pmol} / \mathrm{kg} / \mathrm{min})$ or candesartan $(0.01$ or $0.1 \mathrm{mg} / \mathrm{kg}$ IV) had no significant effect on MAP. Coinfusion of Ang (1-7) and candesartan $(0.01 \mathrm{mg} / \mathrm{kg}$ IV) had no effect on MAP in adult WKY rats (Figure $1(\mathrm{a})$ ) whereas, in aged WKY rats, combined administration of Ang (1-7) and candesartan $(0.01 \mathrm{mg} / \mathrm{kg}$ IV $)$ significantly decreased MAP $(P<0.001)$ (Figure 1(b)). When Ang (1-7) was combined with a 10fold higher dose of candesartan $(0.1 \mathrm{mg} / \mathrm{kg} \mathrm{IV})$, there were significant reductions in MAP in both adult and aged WKY male rats compared with Ang (1-7) alone or candesartan alone $(P<0.01)$. Moreover, this depressor effect of Ang (1-7) was abolished by the addition of the $\mathrm{AT}_{2} \mathrm{R}$ antagonist, PD123319 (50 $\mu \mathrm{g} / \mathrm{kg} / \mathrm{min}$ ), (Figures 2(a) and 2(b)).

In separate groups of animals, we examined the ability of the MasR antagonist A779 to modify the Ang (1-7)-mediated depressor effect. Coinfusion of the Ang (1-7) antagonist A779 with the Ang (1-7)/candesartan combination in adult WKY male rats did not affect Ang (1-7)-mediated depressor response (Figure 3(a)). By contrast, the Ang (1-7)-evoked depressor response, during $\mathrm{AT}_{1} \mathrm{R}$ blockade, in aged WKY rats was in fact abolished by the addition of A779 (Figure 3(b)).

3.2. Localization of ACE2, $A T_{1}, A T_{2}$, and Mas Receptors. Expression levels of ACE as well as angiotensin levels were determined using thoracic sections taken from naïve adult $\mathrm{WKY}$ rats $(n=5)$ and aged WKY rats $(n=4)$. ACE2, $\mathrm{AT}_{1} \mathrm{R}, \mathrm{AT}_{2} \mathrm{R}$, and Mas $\mathrm{R}$ were all localised throughout the entire aortic sections (Figure 4(a)). Expression levels of the $\mathrm{AT}_{1} \mathrm{R}$ were not changed between adult and aged WKY male rats, whereas $\mathrm{ACE} 2, \mathrm{AT}_{2} \mathrm{R}$, and Mas $\mathrm{R}$ expression levels were 


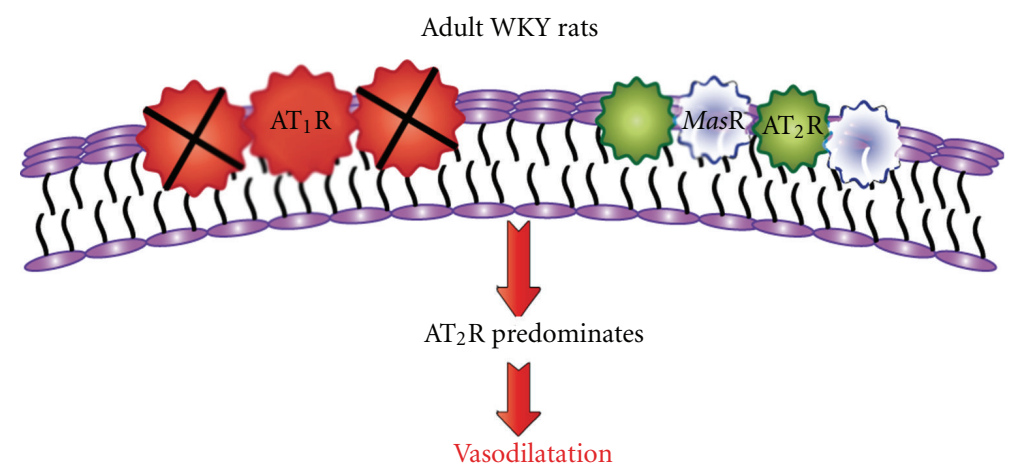

(a)

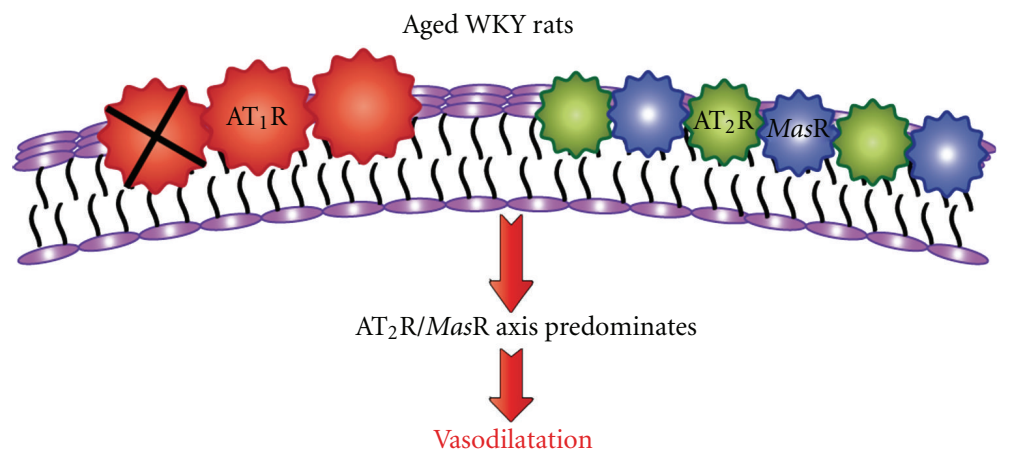

(b)

FIGURE 6: Schema depicting differential mechanisms of Ang (1-7)-mediated vasodepressor effect in adult and aged candesartan-treated rats. $\mathrm{AT}_{1} \mathrm{R}$ expression was similar in aortae from adult and aged rats whereas there was upregulation of $\mathrm{AT}_{2} \mathrm{R}, \mathrm{MasR}$, and $\mathrm{ACE} 2$. Therefore, a lower level of $\mathrm{AT}_{1} \mathrm{R}$ blockade with candesartan $(\mathbf{X})$ was required in aged animals (b) compared with adult animals (a) in order to unmask the vasodilator axis. MasR was not functionally active in adult rats.

all significantly upregulated in aged WKY rats compared to adult WKY rats (Figures $4(\mathrm{~b})-4(\mathrm{e})$ ). Therefore, when expressed relative to $\mathrm{AT}_{1} \mathrm{R}$ levels, each of the vasodilator non$\mathrm{AT}_{1} \mathrm{R}$ components of the RAS was significantly increased in aged WKY rats compared to adult WKY rats (Figure 5).

\section{Discussion}

The main findings of the current study demonstrate for the first time that the depressor effect evoked by Ang (1-7) is preserved in aged normotensive candesartan-treated animals and was sensitive to both $\mathrm{AT}_{2} \mathrm{R}$ and MasR blockade which contrasts with the involvement of only $\mathrm{AT}_{2} \mathrm{R}$ in the effects of Ang (1-7) in adult candesartan-treated rats. Moreover, these findings were consistent with increased $\mathrm{AT}_{2} \mathrm{R}, \mathrm{Mas} \mathrm{R}$, and ACE2 expression in the thoracic aorta of aged WKY rats.

$\mathrm{AT}_{2} \mathrm{R}$-mediated relaxation is a well-established effect in isolated resistance vessels [17-21]. Previous studies have shown $\mathrm{AT}_{2} \mathrm{R}$-mediated vasodilatation in adult conscious rats $[11-14,22]$. The $\mathrm{AT}_{2} \mathrm{R}$-mediated reduction in blood pressure was likely to be a result of direct vasodilatation, rather than a result of decrease in cardiac output, as CGP42112 increased mesenteric and renal conductance in SHR, which was indicative of regional vasodilatation [13]. Furthermore, it is well documented that, in order to unmask any $\mathrm{AT}_{2} \mathrm{R}$-mediated vasodilatation, there needs to be a removal of a tonic $\mathrm{AT}_{1} \mathrm{R}$-mediated vasoconstriction induced by endogenous Ang II [23].

In the current study, acute Ang (1-7) infusion against a background of $\mathrm{AT}_{1} \mathrm{R}$ blockade resulted in a decrease in MAP in adult WKY male rats, and this Ang (1-7) response was mediated exclusively via $\mathrm{AT}_{2} \mathrm{R}$ in adult WKY male rats since the $\mathrm{AT}_{2} \mathrm{R}$ antagonist, $\mathrm{PD} 123319$, abrogated this Ang (1-7)-depressor response, which is consistent with previous findings obtained in both SHR and WKY rats [11]. Of note, the Ang (1-7) antagonist, A779, failed to inhibit vasodepressor responses induced by Ang (1-7) during $\mathrm{AT}_{1} \mathrm{R}$ blockade in adult rats, which confirmed our previous study that also found a 10-fold higher dose of A779 failed to block Ang (1-7) [11]. Thus, at least in this adult model, an exclusive role for Ang (1-7) as an endogenous ligand for the $\mathrm{AT}_{2} \mathrm{R}$ was demonstrated.

In contrast, in the aged setting, the vasodepressor effect of Ang (1-7) was mediated by both $\mathrm{AT}_{2} \mathrm{R}$ and MasR stimulation. Moreover, both candesartan doses (0.01 and $0.1 \mathrm{mg} / \mathrm{kg}$ ) were effective in unmasking Ang (1-7)-mediated vasodepressor responses in aged rats. These results are consistent a 10-fold lower dose of candesartan being used to reveal Ang (1-7)-mediated vasodepressor effects via $\mathrm{AT}_{2} \mathrm{R}$ in SHR compared with WKY rats [11] and point towards an increased sensitivity to $\mathrm{AT}_{1} \mathrm{R}$ blockade in aged rats, as 
we have noted previously [24]. Increased vascular expression of $\mathrm{AT}_{2} \mathrm{R}$ in aging was seen in mesenteric resistance arteries [25] and in thoracic aorta [16]. Thus, Ang (1-7) infusion reduced MAP via $A_{2} R$ in aged WKY rats irrespective of the background dose of candesartan. However, there are numerous reports suggesting the MasR as the functional binding site for Ang (1-7) [7]. For example, Peiro et al. (2007), observed comparable impairment in Ang (1-7)-mediated vasorelaxation as a result of pharmacologic or genetic inhibition of MasR using A779 and MasR-deficient mice, respectively [26]. However, Ang (1-7) evoked vasorelaxation in pig coronary arteries that was attenuated by the $\mathrm{AT}_{2} \mathrm{R}$ antagonist, PD123319, suggesting an $\mathrm{AT}_{2} \mathrm{R}$ involvement [27]. Subsequent studies confirmed that Ang (1-7) can mediate its effects via $\mathrm{AT}_{2} \mathrm{R}$ [8-10]. Ang (1-7)-stimulated NO release in bovine aortic endothelial cells was markedly attenuated by $\mathrm{AT}_{2} \mathrm{R}$ inhibition $(\sim 90 \%)[28,29]$ and to a lesser extent by MasR inhibition ( $\sim 50 \%)$ [28], suggesting activation of multiple receptors by Ang (1-7) which is also consistent with Ang (1-7)-stimulated arachidonic acid release in rabbit vascular smooth muscle cells [30].

More recently, we have demonstrated that chronic treatment with Ang(1-7) was both vaso- and atheroprotective in Apolipoprotein E-deficient mice via both MasR and $\mathrm{AT}_{2} \mathrm{R}$ [31]. Similarly, in the current study, we found that Ang (17) evoked a vasodepressor responses in aged candesartantreated rats that was sensitive to both the $\mathrm{AT}_{2} \mathrm{R}$ antagonist PD123319 and the MasR antagonist A779. This finding suggests that, unlike that in adult normotensive rats, Ang (17) can act via $\mathrm{AT}_{2} \mathrm{R}$ and/or MasR during aging. Therefore, we also examined relative expression levels of the $A_{1} R$, $\mathrm{AT}_{2} \mathrm{R}$, and MasR as well as ACE2 to determine if this could account for the age-related differences in the cardiovascular effects of Ang (1-7). We have now confirmed an increased $\mathrm{AT}_{2} \mathrm{R}$ expression in aortae from aged WKY rats [16], and in addition we have shown, for the first time, a marked increase in expression levels of both MasR and ACE2 in aortic sections from aged WKY rats. Future studies will need to confirm these findings using RT-PCR. These changes in ATR subtype expression fit with our in vivo results and also with other evidence for increased $\mathrm{AT}_{2} \mathrm{R}$ function in aging. For example, $\mathrm{PD} 123319$ can potentiate $\mathrm{AT}_{1} \mathrm{R}$-mediated contractions, which is an indirect measure of $\mathrm{AT}_{2} \mathrm{R}$ relaxation [32, 33], and this "PD123319 potentiation" was enhanced in human coronary microvessels and was positively correlated with age [34]. To our knowledge, there are no reported functional correlates for enhanced Ang (1-7) in aging. At the same time, there was no difference in the expression levels of $\mathrm{AT}_{1} \mathrm{R}$ between adult and aged WKY rats, although a lower level of the $\mathrm{AT}_{1} \mathrm{R}$ block was required to unmask the depressor effect of Ang (1-7) in aged rats. One possible explanation for this difference between aged and adult WKY rats is due to the presence of several potential vasodilator pathways $\left(\mathrm{AT}_{2} \mathrm{R}\right.$, MasR) resulting in preserved vasodilatation in aged WKY rats. This hypothesis is strengthened by the increased ratio of non- $\mathrm{AT}_{1} \mathrm{R}$ components to $\mathrm{AT}_{1} \mathrm{R}$ in aged WKY rats (Figure 6).

In conclusion we have found that Ang (1-7)-mediated vasodepressor activity is preserved with aging. Thus, we can postulate that an increased $\mathrm{AT}_{2} \mathrm{R} / \mathrm{MasR} / \mathrm{ACE} 2$ vasodilator axis relative to $A T_{1} R$ in aged rats is in part responsible for the ability of Ang (1-7) to operate via multiple mechanisms in aging, as opposed to only $\mathrm{AT}_{2} \mathrm{R}$ in adult normotensive candesartan-treated rats.

\section{Acknowledgments}

These studies were funded in part by the National Health and Medical Research Council of Australia (Grant no. 384237).

\section{References}

[1] M. Donoghue, F. Hsieh, E. Baronas et al., "A novel angiotensin-converting enzyme-related carboxypeptidase (ACE2) converts angiotensin I to angiotensin 1-9," Circulation Research, vol. 87, no. 5, pp. E1-E9, 2000.

[2] S. R. Tipnis, N. M. Hooper, R. Hyde, E. Karran, G. Christie, and A. J. Turner, "A human homolog of angiotensinconverting enzyme-cloning and functional expression as a captopril-insensitive carboxypeptidase.," Journal of Biological Chemistry, vol. 275, no. 43, pp. 33238-33243, 2000.

[3] A. J. Trask and C. M. Ferrario, "Angiotensin-(1-7): pharmacology and new perspectives in cardiovascular treatments," Cardiovascular Drug Reviews, vol. 25, no. 2, pp. 162-174, 2007.

[4] G. I. Rice, D. A. Thomas, P. J. Grant, A. J. Turner, and N. M. Hooper, "Evaluation of angiotensin-converting enzyme (ACE), its homologue ACE2 and neprilysin in angiotensin peptide metabolism," Biochemical Journal, vol. 383, no. 1, pp. 45-51, 2004.

[5] R. A. S. Santos and A. J. Ferreira, "Angiotensin-(1-7) and the renin-angiotensin system," Current Opinion in Nephrology \& Hypertension, vol. 16, no. 2, pp. 122-128, 2007.

[6] R. A. S. Santos, M. J. Campagnole-Santos, N. C. V. Baracho et al., "Characterization of a new angiotensin antagonist selective for angiotensin-(1-7): evidence that the actions of angiotensin-(1-7) are mediated by specific angiotensin receptors," Brain Research Bulletin, vol. 35, no. 4, pp. 293-298, 1994.

[7] R. A. S. Santos, A. C. Simoes e Silva, C. Maric et al., "Angiotensin-(1-7) is an endogenous ligand for the G proteincoupled receptor Mas," Proceedings of the National Academy of Sciences of the United States of America, vol. 100, no. 14, pp. 8258-8263, 2003.

[8] C. H. De Castro, R. A. S. Santos, A. J. Ferreira, M. Bader, N. Alenina, and A. P. Almeida, "Evidence for a functional interaction of the angiotensin-(1-7) receptor Mas with AT(1) and AT(2) receptors in the mouse heart," Hypertension, vol. 46, no. 4, pp. 937-942, 2005.

[9] A. M. De Souza, A. G. Lopes, C. P. Pizzino et al., "Angiotensin II and angiotensin-(1-7) inhibit the inner cortex $\mathrm{Na}+$-ATPase activity through AT(2) receptor," Regulatory Peptides, vol. 120, no. 1-3, pp. 167-175, 2004.

[10] L. D. S. Lara, F. Cavalcante, F. O. Axelband, A. M. De Souza, A. G. Lopes, and C. Caruso-Neves, "Involvement of the Gi/o/cGMP/PKG pathway in the AT 2-mediated inhibition of outer cortex proximal tubule $\mathrm{Na}+$-ATPase by Ang-(1-7)," Biochemical Journal, vol. 395, no. 1, pp. 183-190, 2006.

[11] P. E. Walters, T. A. Gaspari, and R. E. Widdop, "Angiotensin(1-7) acts as a vasodepressor agent via angiotensin II type 2 receptors in conscious rats," Hypertension, vol. 45, no. 5, pp. 960-966, 2005. 
[12] M. N. Barber, D. B. Sampey, and R. E. Widdop, "AT2 receptor stimulation enhances antihypertensive effect of AT1 receptor antagonist in hypertensive rats," Hypertension, vol. 34, no. 5, pp. 1112-1116, 1999.

[13] X. C. Li and R. E. Widdop, "AT2 receptor-mediated vasodilatation is unmasked by AT 1 receptor blockade in conscious SHR," The British Journal of Pharmacology, vol. 142, no. 5, pp. 821-830, 2004.

[14] S. Bosnyak, I. K. Welungoda, A. Hallberg, M. Alterman, R. E. Widdop, and E. S. Jones, "Stimulation of angiotensin AT(2) receptors by the non-peptide agonist, Compound 21, evokes vasodepressor effects in conscious spontaneously hypertensive rats," The British Journal of Pharmacology, vol. 159, no. 3, pp. 709-716, 2010.

[15] M. Wang, G. Takagi, K. Asai et al., "Aging increases aortic MMP-2 activity and angiotensin II in nonhuman primates," Hypertension, vol. 41, no. 6, pp. 1308-1316, 2003.

[16] R. E. Widdop, A. Vinh, D. Henrion, and E. S. Jones, "Vascular angiotensin AT2 receptors in hypertension and ageing," Clinical and Experimental Pharmacology and Physiology, vol. 35, no. 4, pp. 386-390, 2008.

[17] C. Dimitropoulou, R. E. White, L. Fuchs, H. Zhang, J. D. Catravas, and G. O. Carrier, "Angiotensin II relaxes microvessels via the $\mathrm{AT}(2)$ receptor and $\mathrm{Ca} 2+$-activated $\mathrm{K}+$ (BKCa) channels," Hypertension, vol. 37, no. 2 I, pp. 301-307, 2001.

[18] K. Matrougui, B. I. Levy, and D. Henrion, "Tissue angiotensin II and endothelin-1 modulate differently the response to flow in mesenteric resistance arteries of normotensive and spontaneously hypertensive rats," The British Journal of Pharmacology, vol. 130, no. 3, pp. 521-526, 2000.

[19] K. Matrougui, L. Loufrani, C. Heymes, B. I. Lévy, and D. Henrion, "Activation of AT2 receptors by endogenous angiotensin II is involved in flow-induced dilation in rat resistance arteries," Hypertension, vol. 34, no. 4 I, pp. 659-665, 1999.

[20] R. E. Widdop, K. Matrougui, B. I. Levy, and D. Henrion, "AT2 receptor-mediated relaxation is preserved after long-term AT1 receptor blockade," Hypertension, vol. 40, no. 4, pp. 516-520, 2002.

[21] D. Henrion, N. Kubis, and B. I. Lévy, "Physiological and pathophysiological functions of the AT2 subtype receptor of angiotensin II from large arteries to the microcirculation," Hypertension, vol. 38, no. 5, pp. 1150-1157, 2001.

[22] R. M. Carey, N. L. Howell, X. H. Jin, and H. M. Siragy, "Angiotensin type 2 receptor-mediated hypotension in angiotensin type-1 receptor-blocked rats," Hypertension, vol. 38, no. 6, pp. 1272-1277, 2001.

[23] R. E. Widdop, E. S. Jones, R. E. Hannan, and T. A. Gaspari, "Angiotensin AT2 receptors: cardiovascular hope or hype?" The British Journal of Pharmacology, vol. 140, no. 5, pp. 809824, 2003.

[24] E. S. Jones, M. J. Black, and R. E. Widdop, "Angiotensin AT2 receptor contributes to cardiovascular remodelling of aged rats during chronic AT1 receptor blockade," Journal of Molecular and Cellular Cardiology, vol. 37, no. 5, pp. 1023-1030, 2004.

[25] F. Pinaud, A. Bocquet, O. Dumont et al., "Paradoxical role of angiotensin II type 2 receptors in resistance arteries of old rats," Hypertension, vol. 50, no. 1, pp. 96-102, 2007.

[26] C. Peiro, S. Vallejo, F. Gembardt et al., "Endothelial dysfunction through genetic deletion or inhibition of the G proteincoupled receptor Mas: a new target to improve endothelial function," J. Hypertenss, vol. 25, no. 12, pp. 2421-2425, 2007.
[27] G. Gorelik, L. A. Carbini, and A. G. Scicli, "Angiotensin 1-7 induces bradykinin-mediated relaxation in porcine coronary artery," Journal of Pharmacology and Experimental Therapeutics, vol. 286, no. 1, pp. 403-410, 1998.

[28] G. Wiemer, L. W. Dobrucki, F. R. Louka, T. Malinski, and H. Heitsch, "AVE 0991, a nonpeptide mimic of the effects of angiotensin-(1-7) on the endothelium," Hypertension, vol. 40, no. 6, pp. 847-852, 2002.

[29] H. Heitsch, S. Brovkovych, T. Malinski, and G. Wiemer, "Angiotensin-(1-7)-stimulated nitric oxide and superoxide release from endothelial cells," Hypertension, vol. 37, no. 1, pp. 72-76, 2001.

[30] M. M. Muthalif, I. F. Benter, M. R. Uddin, J. L. Harper, and K. U. Malik, "Signal transduction mechanisms involved in angiotensin-(1-7)-stimulated arachidonic acid release and prostanoid synthesis in rabbit aortic smooth muscle cells," Journal of Pharmacology and Experimental Therapeutics, vol. 284, no. 1, pp. 388-398, 1998.

[31] S. Tesanovic, A. Vinh, T. A. Gaspari, D. Casley, and R. E. Widdop, "Vasoprotective and atheroprotective effects of angiotensin (1-7) in apolipoprotein E-deficient mice," Arteriosclerosis, Thrombosis, and Vascular Biology, vol. 30, no. 8, pp. 1606-1613, 2010.

[32] R. E. Hannan, E. A. Davis, and R. E. Widdop, "Functional role of angiotensin II AT(2) receptor in modulation of $\mathrm{AT}(1)$ receptor-mediated contraction in rat uterine artery: involvement of bradykinin and nitric oxide," The British Journal of Pharmacology, vol. 140, no. 5, pp. 987-995, 2003.

[33] A. S. Zwart, E. A. Davis, and R. E. Widdop, "Modulation of AT1 receptor-mediated contraction of rat uterine artery by AT(2) receptors," The British Journal of Pharmacology, vol. 125, no. 7, pp. 1429-1436, 1998.

[34] W. W. Batenburg, I. M. Garrelds, C. C. Bernasconi et al., "Angiotensin II type 2 receptor-mediated vasodilation in human coronary microarteries," Circulation, vol. 109, no. 19, pp. 2296-2301, 2004. 


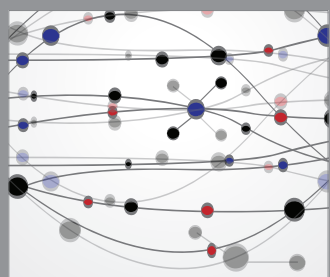

The Scientific World Journal
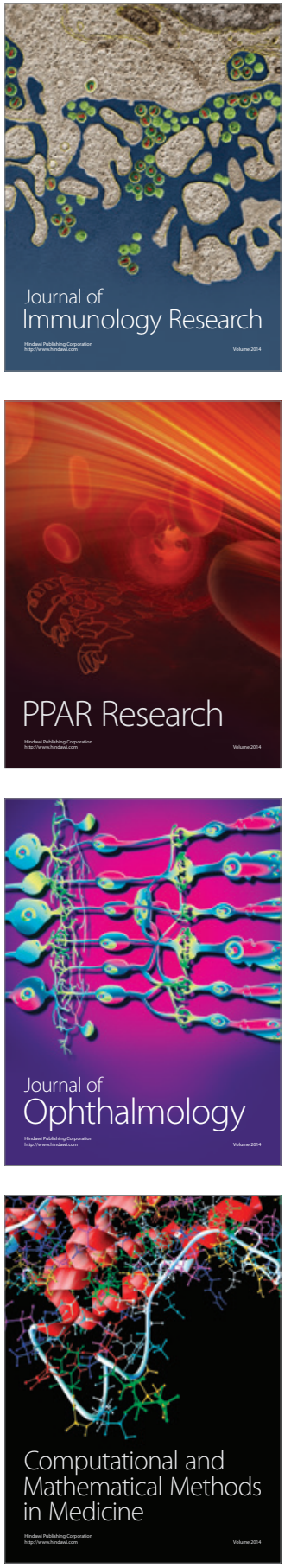

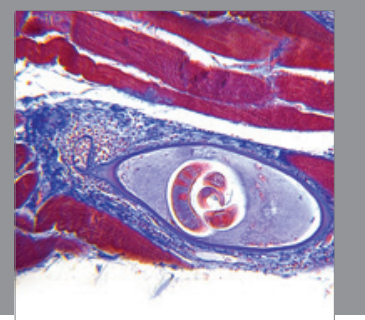

Gastroenterology

Research and Practice
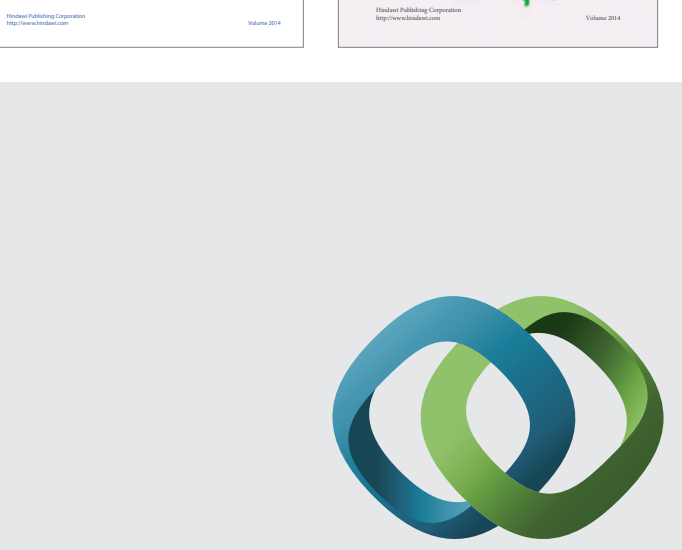

\section{Hindawi}

Submit your manuscripts at

http://www.hindawi.com
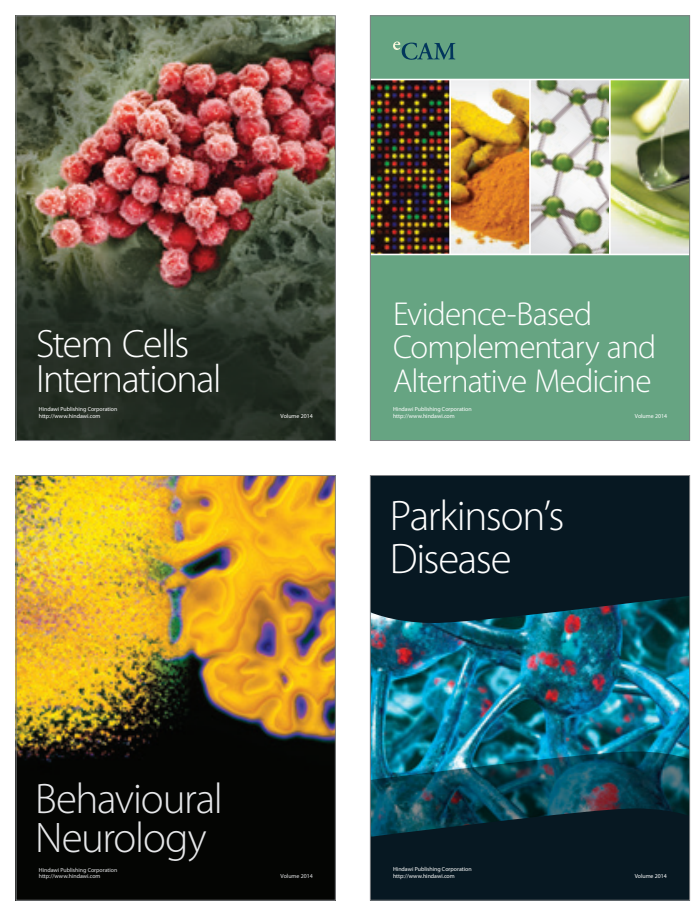

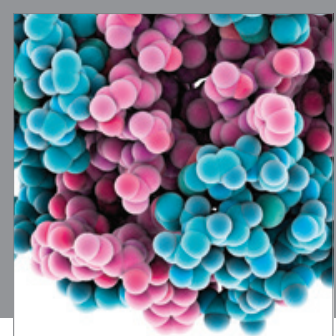

Journal of
Diabetes Research

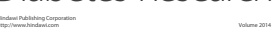

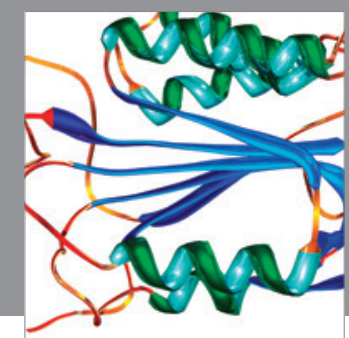

Disease Markers
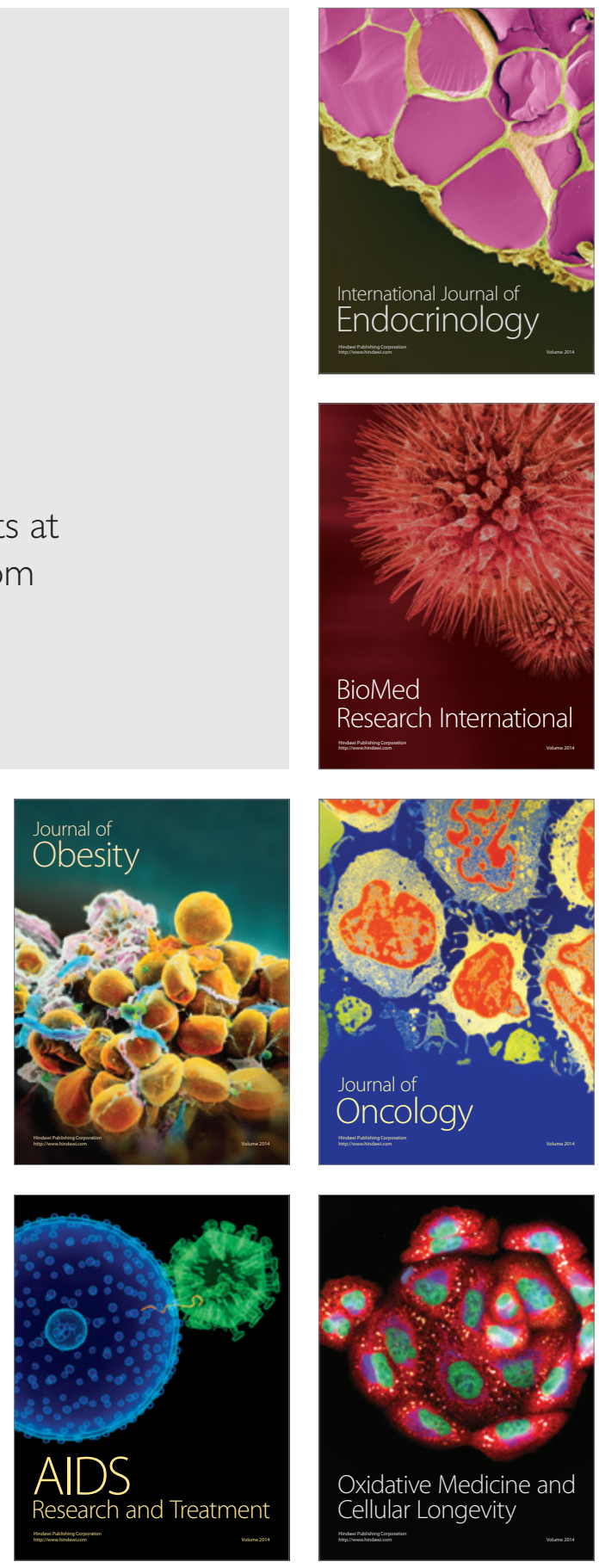